\title{
VOMITING OF UNCERTAIN ORIGIN IN YOUNG INFANTS
}

\author{
BY \\ B. S. B. WOOD and ROY ASTLEY \\ From the Children's Hospital, Birmingham
}

(RECEIVED FOR PUBLICATION JUNE 3, 1952)

For the past few years we have been interested in vomiting in young infants, and especially in those cases where no organic basis for the symptoms could be discovered.

\section{Historical Note}

The earlier records of vomiting in infancy, as would be expected, mainly concern infective causes and even Armstrong's (1777) description of ' pyloric stenosis' is included in a section on watery gripes. Later, as the popularity of artificial feeding increased during the nineteenth century, this factor became prominent and Henoch (1889) remarked that improper feeding, especially over-feeding, was the usual cause of dyspepsia. At about this time it was suggested that the infant's constitution might be a contributory cause, Dewees (1834) dividing vomiting into idiopathic and sympathetic, while Rotch (1896) postulated that irritation of large sympathetic ganglia might be responsible for vomiting in some cases.

Up to the turn of the last century food and constitution were the most important diagnostic factors once infective causes had been, as far as possible, excluded. Since then, however, with the re-discovery of pyloric stenosis, the advance of surgery and the application of such aids as radiology, more and more cases of idiopathic vomiting are being recognized as having an organic basis.

\section{Present Study}

A consecutive series of 100 babies admitted to hospital under 6 months of age because of vomiting without diarrhoea was closely studied and followed up. In 82 the vomiting could be ascribed to some organic disease such as pyloric stenosis, intestinal obstruction, or infection; however, the cause remained uncertain in 18, even after a stay in hospital of several weeks (Wood, 1951).
By selection 46 such undiagnosed cases were collected over a further two years; they were examined clinically and radiologically, and followed up until their symptoms abated. Twenty-four of these 46 were considered finally to have extrinsic factors as the main cause of the vomiting, underfeeding being the commonest. This has been discussed elsewhere (Wood, 1952).

In the remaining 22 infants the vomiting appeared to be of uncertain aetiology, and it is the purpose of this communication to describe their symptomatology, to speculate on the possible aetiology, and to suggest fruitful lines of treatment.

The 22 cases seemed to fall into two sharply demarcated groups. In one the onset was gradual, the vomiting was not typically projectile but it continued for more than six months in every case. These infants are termed 'persistent vomiters of uncertain origin'.

In the second group the onset was abrupt, the vomiting was forceful, often frankly projectile, but had ceased in all the babies by the age of 3 months; they are therefore described as "non-persistent vomiters of uncertain origin'. This method of classification is helpful as it carries a certain prognostic implication as well.

The two groups roughly correspond with Freudenberg's (1942) division into atonic and spastic vomiting.

Fig. 1 and Table 1 compare the two groups and

TABLE 1

Comparison of Average Data in Persistent and Non-Persistent VOMITING OF UNCERTAIN ORIGIN

\begin{tabular}{|c|c|c|c|}
\hline & & Persistent & Non-Persistent \\
\hline $\begin{array}{l}\text { Duration of vomiting } \\
\text { Age at lowest weight } \\
\text { Age at reaching expected weight } \\
\text { Effect of mixed feeding } \quad . .\end{array}$ & $\cdots$ & $\begin{array}{l}29 \text { weeks } \\
20 \text { weeks } \\
\text { About } 1 \text { year } \\
\text { Cure }\end{array}$ & $\begin{array}{l}7 \text { weeks } \\
5 \text { weeks } \\
25 \text { weeks } \\
\text { None }\end{array}$ \\
\hline
\end{tabular}


suggest that they are different syndromes, which are therefore considered under separate headings.

\section{Persistent Vomiting of Uncertain Origin}

There were 10 cases in this group (two in 100 consecutive cases of vomiting without diarrhoea under 6 months of age).

From Table 2 certain features emerge. Most of the infants were breast fed soon after birth and

TABLE 2

Persistent Vomiting of UnCertain Origin

\begin{tabular}{|c|c|c|c|c|c|}
\hline $\begin{array}{c}\text { Total number } \\
\text { Males } \\
\text { Firstborn } \\
\text { Breast fed }\end{array}$ & $\begin{array}{l}\cdots \\
\cdots \\
\cdots\end{array}$ & $\begin{array}{l}\cdots \\
\cdots \\
\cdots\end{array}$ & $\begin{array}{l}. . \\
\cdots \\
.\end{array}$ & $\begin{array}{l}\cdots \\
\cdots \\
\cdots\end{array}$ & $\begin{array}{r}10 \\
8 \\
3 \\
7\end{array}$ \\
\hline $\begin{array}{l}\text { Average age } \\
\text { At onset } \\
\text { On admission }\end{array}$ & & 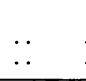 & $\therefore$ &.. & $\begin{array}{r}3 \\
12 \\
12 \text { weeks }\end{array}$ \\
\hline $\begin{array}{l}\text { Vomiting } \\
\text { From birth } \\
\text { Duration bef } \\
\text { Projectile }\end{array}$ & $\begin{array}{l}\ldots \\
\text { fore adn } \\
. .\end{array}$ & mission & 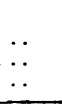 & $\begin{array}{l}\cdots \\
\cdots \\
\cdots\end{array}$ & $\begin{array}{l}5 \\
9 \text { weeks } \\
4 \text { reported, } 1 \text { observed }\end{array}$ \\
\hline $\begin{array}{c}\text { Content of } \mathbf{v} \\
\text { Mucus } \\
\text { Blood } \\
\text { Bile } \\
\end{array}$ & $\begin{array}{l}\text { vomits } \\
\ldots \\
\ldots \\
\cdots \\
\end{array}$ & $\begin{array}{l}\cdots \\
\cdots \\
\cdots\end{array}$ & $\begin{array}{l}. . \\
\cdots \\
\cdots\end{array}$ & $\begin{array}{l}\cdots \\
\cdots \\
\cdots\end{array}$ & $\begin{array}{l}5 \\
2 \\
1 \\
\end{array}$ \\
\hline Constipation & . & .. & . & .. & 5 \\
\hline Average admissio & on weigh & & . & .. & $85 \%$ of expected weight \\
\hline 'Hypertonia' & . & .. & $\cdots$ & $\ldots$ & 3 \\
\hline Aerophagy (clinic & cal) & .. & $\cdots$ & $\cdots$ & 1 \\
\hline Hunger and cryin & ag after & feed & . & $\ldots$ & 3 \\
\hline Upper abdominal & 1 distens & sion & . & $\ldots$ & 2 \\
\hline Visible peristalsis & .. & . & . & $\cdots$ & 1 \\
\hline Palpable tumour & & . &. & $\ldots$ & 0 \\
\hline Average stay in $h$ & hospital & & $\cdots$ & ..1 & 5 weeks \\
\hline Mortality . . & .. & . & . & $\cdots$ & 0 \\
\hline \multicolumn{5}{|c|}{ Average age at cessation of vomiting .. } & 32 weeks \\
\hline
\end{tabular}

therefore at the onset of symptoms, and there was little evidence of under-feeding or aerophagy. The condition seemed to progress slowly, the duration of symptoms before admission averaging nine weeks. Oesophagitis or gastritis occurred in a number as shown by blood (two cases) and mucus (five cases) in the vomit. There was little or no evidence of obstruction to the passage of food from the stomach; gastric peristalsis and upper abdominal distension were seldom seen and no pyloric tumour was ever felt by the authors.

The severity of the condition can be gauged by the average hospital stay of five weeks (maximum 11 weeks) and the average weight of $85 \%$ of the expected weight, the lowest being $60 \%$.

Radiological Findings. The 10 children in this group had repeated barium studies of the upper alimentary tract. These were negative until recently, when follow-up examinations showed abnormalities in four. In these the cardia was within the thorax; there was a small loculus of thoracic stomach and gastro-oesophageal reflux occurred ('congenital short oesophagus ').

Illustrative Case Histories. The following case histories illustrate certain features of the condition and its treatment.

SeVERE INTRACTABle Vomiting. Case D had recurrent vomiting, often with altered blood, from a few days old. On examination at 15 weeks he was an alert, smiling, precocious infant, very wasted but quite active. His vomits nearly always contained large amounts of mucus. Fig. 1 shows how he began to gain weight in hospital after complementary feeding and stomach wash-outs were started. He relapsed several times, however, once so severely that he had to be put on intravenous fluids, and only ceased vomiting at about 34 weeks of age. Repeated radiographic examinations with barium were negative until at the age of $4 \frac{1}{2}$ years a small gastric loculus was demonstrated to lie above the diaphragm.

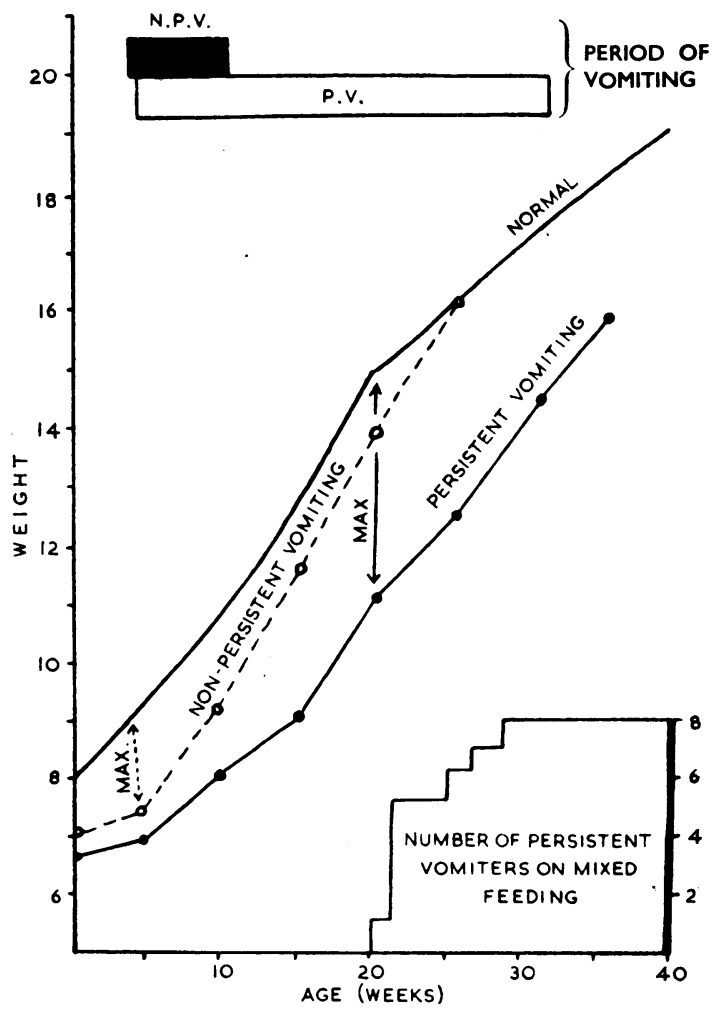

Fig. 1.-Weight chart of Case D showing the prolonged duration of the vomiting and the cure with mixed feeding. The upper line indicates normal expected weight; he had not reached this by his first birthday. 
ImProvement With Thick, High-CALORIE FeEDS. Case No: 47 was a twin whose brother had had pyloric stenosis treated by Rammstedt's operation. He started to vomit at about 10 weeks of age and was admitted two weeks later for laparotomy as a case of suspected pyloric stenosis. A barium meal was normal. At operation no tumour was found and he continued to vomit afterwards, although the pyloric muscle had been incised. When he was discharged he was offered a very thick, high calorie cornflour feed of about 30 calories per ounce. His vomiting continued unabated but his weight rose and in fact equalled that of his twin 'pyloric' brother, who was not vomiting but receiving a more normal food intake.

Aetiology. The similarity between these cases of persistent vomiting of uncertain origin and mild cases of gastro-oesophageal incompetence associated with a partial thoracic stomach includes the features of onset soon after birth, haematemeses, intermittent progress and great improvement on introducing mixed feeding. Indeed, four of them, despite repeated negative radiological findings on previous occasions, are now found to have a small, partially thoracic, stomach.

It is possible that these four were examples of sliding herniae, sometimes present, sometimes reduced, or even that the vomiting itself led to the development of such herniae in the course of time.

It is perhaps more likely that the anatomical abnormality was present throughout life but that the $x$-ray examination failed to reveal it because at the time of examination gastro-oesophageal reflux was absent or minimal; when fluoroscopy happened to coincide with the presence of reflux the abnormality became apparent.

In the absence of reflux it is sometimes very difficult to demonstrate that the terminal portion of the gullet is really stomach. The barium tends to pass from the oesophagus in a stream of constant width that fails to distend the often tiny loculus of thoracic stomach. There may be no constriction at the site of the cardia; the hiatus and the gastrooesophageal angle may appear normal. It is often only when reflux is induced that the barium fills the thoracic stomach completely, showing its size, its often asymmetrical situation relative to the oesophagus, and the site of a change of mucosal pattern. The following example may be quoted. During one examination all tests failed to provoke gastrooesophageal reflux; hiatal anatomy and function appeared entirely normal. As the rather prolonged examination was about to be terminated as negative, the child began to cry; with the resultant raised intra-abdominal pressure, re-application of the tests for reflux immediately provoked its occurrence and revealed that the cardia lay above the diaphragm.
It is evident, therefore, that when symptoms suggest gastro-oesophageal incompetence one negative x-ray examination must be treated with reserve. Repeated examinations may be necessary to establish the diagnosis.

In the remaining six children in this group, where the vomiting is still of unknown origin, the possibility of gastro-oesophageal incompetence due to a yet undiagnosed small amount of intrathoracic stomach must therefore remain. Failing this, they are possibly mild or borderline examples of the condition of chalasia (Neuhauser and Berenberg, 1947), i.e., a lax but normally situated cardia. For reasons given elsewhere (Carré and Astley, 1952) it is thought that certainly some cases of chalasia are in fact examples of partial thoracic stomach.

Re-examination of the case records has failed to reveal any point of difference between those with and those without demonstrable anatomical defect; it would seem reasonable, therefore, to postulate the presence of a gastro-oesophageal dysfunction of some kind in all.

Treatment. These cases responded best to treatment on the lines usually adopted in gastrooeosophageal incompetence (propping in the vertical position, increasing and thickening the feeds), while in most cases the introduction of a mixed diet cured the symptoms. The exact differentiation of the defect is therefore of less importance as the treatment seems to be the same.

'Vomiting itself is undesirable' because it ' fills attendants with gloom' (Jacoby, 1946) but it is worth recalling that none in this series died. These facts, together with a workable line of treatment, have enabled us to tackle this disorder with some degree of confidence and even of enthusiasm.

\section{Non-persistent Vomiting of Uncertain Origin or Pseudo-pyloric Stenosis}

There were 12 cases (three in 100 consecutive cases of vomiting without diarrhoea under 6 months of age) in this group. They are given some prominence because, although few, they closely resemble pyloric stenosis; on this account they are sometimes subjected to operation, as happened in five of the 12; four others were given atropine methyl nitrate (' eumydrin') for the same reason.

The summary of the findings is given in Table 3, where they are compared with those in a series of 75 cases of hypertrophic pyloric stenosis. The close similarity is apparent.

- It will be seen, however, that in non-persistent vomiting of uncertain origin the children are less likely to be boys, are rarely breast-fed at the onset, 
TABLE 3

Comparison of Non-Persistent Vomiting of UNCERTAIN Origin AND HyPERTROPHIC PyLORIC Stenosis

\begin{tabular}{|c|c|c|c|c|c|}
\hline & & & & $\begin{array}{c}\text { Non- } \\
\text { Persistent } \\
\text { Vomiting } \\
\text { of } \\
\text { Uncertain } \\
\text { Origin }\end{array}$ & $\begin{array}{l}\text { Hyper- } \\
\text { trophic } \\
\text { Pyloric } \\
\text { Stenosis }\end{array}$ \\
\hline $\begin{array}{l}\text { Total number } \\
\text { Males } \\
\text { Firstborn } \\
\text { Breast fed } \\
\end{array}$ & $\begin{array}{l}\cdots \\
\cdots \\
\cdots\end{array}$ & $\begin{array}{l}\cdots \\
\cdots \\
\end{array}$ & $\begin{array}{l}\cdots \\
\cdots \\
\cdots\end{array}$ & $\begin{array}{r}12 \\
8 \\
7 \\
2 \\
\end{array}$ & $\begin{array}{c}75 \\
10 * \\
5 \frac{1}{2} \\
5 \frac{1}{2} \\
\end{array}$ \\
\hline \multicolumn{2}{|c|}{$\begin{array}{l}\text { Average age } \\
\text { At onset (weeks) } \\
\text { On admission (weeks) } \\
\end{array}$} & .. & $\therefore$ & $\begin{array}{l}3 \\
51\end{array}$ & $\begin{array}{ll}31 \\
5 \frac{1}{4}\end{array}$ \\
\hline \multicolumn{4}{|c|}{$\begin{array}{llll}\text { Vomiting } & & \\
\text { From birth } & \ldots & \ldots & \\
\text { Duration before admission (weeks) } \\
\text { Projectile } & \ldots & \ldots & \ldots\end{array}$} & $\begin{array}{l}3 \\
2 \\
7\end{array}$ & $\begin{array}{c}1 \\
2 t \\
10\end{array}$ \\
\hline 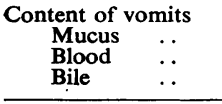 & $\begin{array}{l}\cdots \\
\cdots \\
\end{array}$ & $\begin{array}{l}\cdots \\
\cdots \\
\end{array}$ & $\begin{array}{l}\cdots \\
\cdots \\
\end{array}$ & $\begin{array}{l}2 \\
1 \\
0\end{array}$ & $\begin{array}{l}2 \\
1 \frac{1}{2} \\
0 \cdot 8\end{array}$ \\
\hline Constipation.. & .. & .. & . & 7 & 9 \\
\hline \multicolumn{4}{|c|}{ 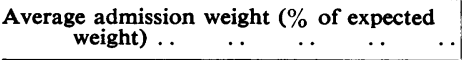 } & 80 & 85 \\
\hline Hypertonia & .. & . & .. & $\cdot 2$ & 2 \\
\hline Aerophagy (clinical) & . & . & $\therefore$ & 3 & 2 \\
\hline \multicolumn{3}{|c|}{ Hunger and crying after feed } & .. & 3 & 1 \\
\hline \multicolumn{3}{|c|}{ Upper abdominal distension } & .. & 5 & $9 \frac{1}{2}$ \\
\hline Visible peristalsis & $\cdots$ & $\cdots$ & $\ldots$ & 5 & $6 \frac{1}{2}$ \\
\hline Palpable tumour & .. & .. & .. & 8 & $11 \frac{1}{2}$ \\
\hline $\begin{array}{c}\text { Barium meal } \\
\text { Spasm } \\
\text { Aerophagy }\end{array}$ & $\cdots$ & $\because$ & $\cdots$ & $\begin{array}{l}4 \\
2 \\
\end{array}$ & \\
\hline Mortality & . & .. & . & 0 & $0 \cdot 3$ \\
\hline \multicolumn{4}{|c|}{ Average age at cessation of vomiting (weeks) } & 10 & \\
\hline
\end{tabular}

* Figures in italics are expressed per 12 cases of hypertrophic stenosis so that the two columns are directly comparable.

tend to be more fretful and cry after feeds, and, although visible peristalsis occurs nearly as frequently as in pyloric stenosis, it is not often as well marked. All these factors are of relative value only, so one is left with the 'tumour' and the $\mathrm{x}$-ray appearances.

The Tumour. In our experience, and in the opinion of some of our colleagues, with whom we have discussed this problem, there is a difference in the consistency of the mass in non-persistent vomiting of uncertain origin. It is only felt at a time when the true pyloric tumour is really hard, just before or just after a vomit, and then is less well defined and softer than in frank pyloric stenosis. In addition, it relaxes quickly and, unlike a true tumour, cannot be felt again and again once it is found. In this series when a mistake occurred and no hypertrophied muscle was found at operation, the observer always in retrospect remarked that the mass was perhaps not quite typical. Such was our own finding in the two cases where we felt 'tumours' which were not subsequently confirmed; they both appeared momentarily and relaxed quickly. Even in Finkelstein's (1919) case where the tumour was felt by all who were on the ward round it was softer than usual.

Radiological Findings. Four of the 12 babies in this group, when examined by a small, food-free barium meal, presented the radiological picture we consider indicative of infantile pylorospasm.

There was narrowing of the pyloric antrum that simulated to a varying degree the direct $x$-ray evidence of hypertrophic pyloric stenosis. Although this narrowing persisted for periods from 10 minutes to over an hour, it lacked the absolute constancy and aperistalsis of the stenosed segment in the latter condition. Continued observation showed that eventually peristalsis began to cross the narrowing, momentarily widening it; then the segment became shorter and widened from the proximal end, so that it was more tapering in shape and finally of normal calibre (Fig. 2).

In the normal infant the pyloric antrum often takes one or two minutes at the beginning of an examination to widen to its full width, possibly as a valvular mechanism related to that present anatomically in certain lower animals (Forssell, 1923; 1939). 'Infantile pylorospasm ' appears to be a retardation of this normal process and is perhaps a delay in relaxation rather than a spasm.

The narrow segment may cause considerable difficulty in its differentiation from hypertrophic pyloric stenosis; indeed, the first two instances we encountered were misinterpreted. The radiological diagnosis is considered more fully elsewhere (Astley, 1952).

Illustrative Cases. The following cases illustrate these diagnostic difficulties.

Clinical Misdiagnosis. G, a first baby, bottle-fed from birth, was admitted to hospital at the age of 5 weeks. Vomiting had occurred from birth, but at 2 weeks it became more severe, projectile in character and contained mucus with, at times, a little altered blood. On examination she was a lusty infant within $5 \%$ of her expected weight and took her feeds well. A contractile mass was felt to harden and relax in the pyloric area towards the end of the feed on three occasions by two observers, including one of the authors. Nearly every feed was followed by an extremely forcible vomit, which was projected a distance of at least a foot and a half. At operation, however, no pyloric tumour was found and no other cause for the yomiting was discovered.

Her post-operative course was stormy as she continued to vomit explosively despite atropine methyl nitrate and then nitroglycerine (Falle, 1948): Indeed, 


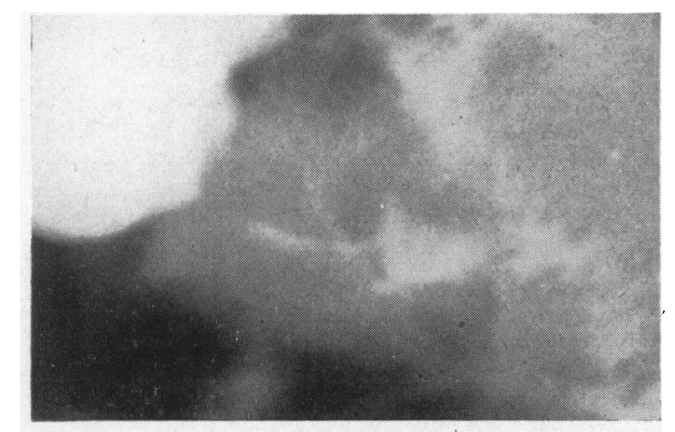

2 (a)
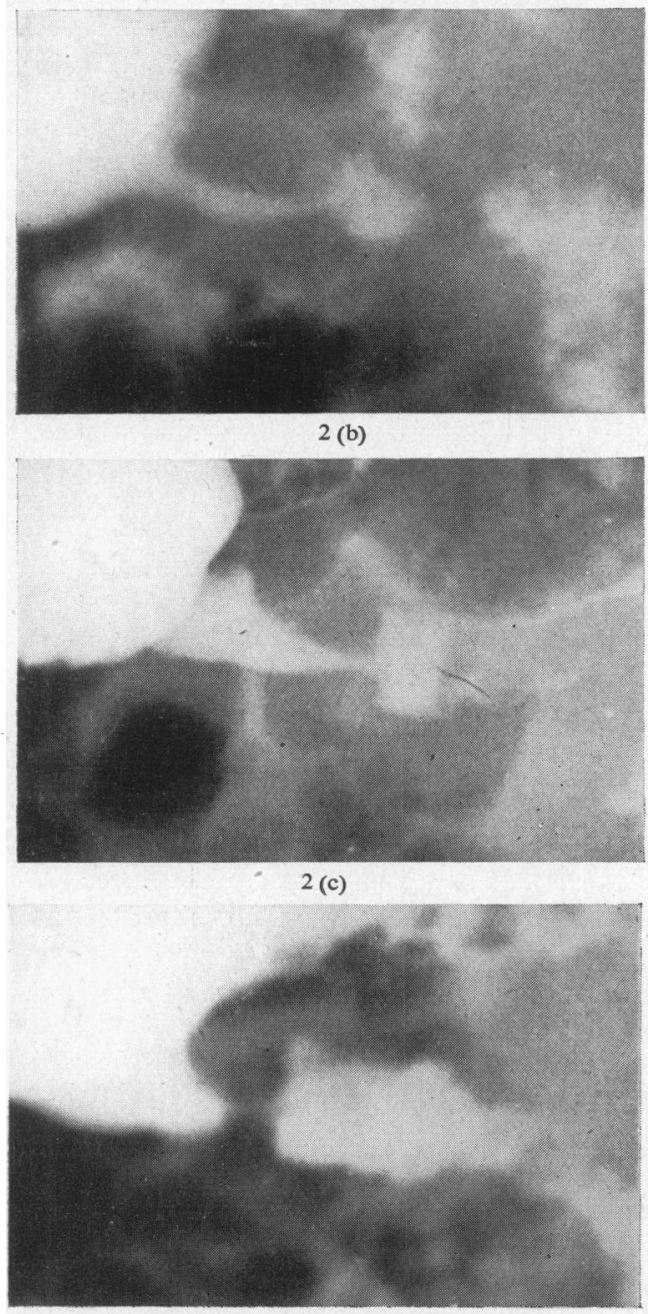

2 (d)

Fig. 2.-Case 132 showed 'pylorospasm': A, pre-pyloric narrowing simulating hypertrophic stenosis; $B$ and $C$, the gradual widening of this segment over half-an-hour; $D$, normal appearances four days later. (Reproduced by permission of the Editor of the British Journal of Radiology. after one dose of the latter drug she burst the abdominal wound because of the force of her vomiting. This exactly parallels a similar case of Rocher's (1931) which suffered the same mishap because of persistent extremely forceful vomiting after operation. After a further two weeks of intravenous feeding breast milk was offered by mouth and she began to keep her feeds down, regaining her expected weight by 21 weeks.

Clinical and Radiological Misinterpretation. - Case 81 . Vomiting began at 4 days when the baby was put on the bottle. The vomiting was projectile and contained milk curds 10 hours after her last milk feed, indicating some degree of gastric retention. A pyloric ' tumour' had been palpated by another observer and at 12 days old she was admitted for operation. Clinical examination by one of us failed to reveal a palpable pyloric tumour. A barium meal showed some prepyloric narrowing while, with the examining finger in that area, it was possible to palpate a soft mass which, however, did not harden to anything like the consistency of a true pyloric tumour. The stomach emptied fairly well but the narrowing of the pyloric area was constant for at least 15 minutes.

At operation no tumour was found and the normal pyloric muscle was incised. A barium meal three weeks after operation showed no abnormality and, although slower to gain weight than most, she was over $16 \mathrm{lb}$. at 6 months and had not vomited since discharge at 10 weeks old.

Aetiology. It might be argued that some of these infants are early or mild cases of pyloric stenosis where pylorospasm without hypertrophy accounts for their symptoms. No case of ours has been observed to proceed from spasm to true hypertrophic stenosis, although Uhr (1932) described such an instance. This raises the old question recently discussed by McKeown, MacMahon and Record (1951) of whether an acquired spasm can lead to stenosis, and it is apparent that much still remains to be clarified on this point. Confusion of terminology (Sauer, 1924) still exists and when one remembers that in many continental centres the diagnosis of pyloric stenosis is based on $x$-ray findings (which can occasionally be misleading) rather than palpation of a tumour and is rarely supported by the acid test of operation, it is possible that some of these discrepancies can be explained. From the radiological standpoint alone it is possible that some of Meuwissen and Slooff's (1934) cases were in fact examples of spasm and not of true hypertrophic stenosis.

In the present series five were operated on and found to have no hypertrophy; in the other seven the condition subsided more rapidly than is usual in true pyloric stenosis.

The question of pylorospasm was first raised by Finkelstein (1919), who emphasized its rarity, 
deploring that 'English doctors call all cases of vomiting without obvious cause " pylorospasm", Recent British opinion has hardened against such a diagnosis. Thompson and Gaisford (1935) believed that it "exists more in the mind of the paediatrician than in the abdomen of the child', while Field (1941) was its solitary supporter at a meeting of the Royal Society of Medicine.

In the present series the unequivocal projectile vomits containing mucus, associated with constipation, visible peristalsis, and the frequent presence of a contractile mass palpable in the pyloric area, all point to some obstructive factor. When the radiological findings and the self-limited course are taken into account the similarity to pyloric stenosis is apparent.

Including the four mentioned previously, pylorospasm has been observed radiologically in 10 babies, vomiting for a variety of reasons (Astley, 1952). The most constant factor was aerophagy, which was a pronounced feature in six (in two there were gross anatomical causes for swallowing air). It is interesting to speculate whether a reflex failure of relaxation occurs to prevent excessive amounts of air from passing into the small intestine.

It is evident that the radiological picture described is not pathognomonic of non-persistent vomiting of uncertain origin nor found in all instances of it. A reasonable attitude is to regard it not as a separate entity but as a non-specific phenomenon that may occur in this condition and cause difficulty in its radiological differentiation from hypertrophic pyloric stenosis.

In considering the possible causes for the spasm in the present series it is of interest that seven of the 12 cases had a definite history of beginning to vomit a day or so after they had been put on the bottle, and in two others (making a total of nine) such a sequence could not be excluded, the mothers' stories being indefinite; only two cases of the other 34 with vomiting of unknown origin had a similar story. A review of the literature on this point is not very rewarding although cases reported by Morse (1911), Koplik (1913), Kerley (1920) and Finkelstein (1919) had somewhat similar feeding histories. Of recent cases, Falle's patient (1948) was breast-fed but Mann and Anscombe's (1948) began to vomit on changing to the bottle. This finding may be due to chance, to mechanical differences between nipple and teat, rate of milk flow, or to difference in the milk itself.

Treatment. It seems that laparotomy (five cases), even if a modified Rammstedt's procedure (two cases) is performed, should be avoided; there was no miraculous cessation of vomiting as described by
Browne (1931) and Thompson and Gaisford (1935). One case was complicated by a burst abdomen, another by wound sepsis following operation; all this argues against any laxity in differentiating between true pyloric stenosis and its imitators, and against operation on suspected cases of spasm as a form of investigation or of treatment (Mann and Anscombe, 1948; Davison, 1951). While maintaining a plea against unnecessary operation it is worth recalling that in this series, although no case of non-persistent vomiting of uncertain origin has died as a result of such an operation, two cases of true pyloric stenosis have died largely on account of delay in diagnosis and operation.

The effect of antispasmodics was disappointing, but this may be misleading on the score that only those babies who fail in 'medical' treatment tend to be admitted to hospital and our series consists mainly of hospital admissions. Nitroglycerine was used in one case in view of the experience of Falle (1948) but it had no appreciable effect. Most of these cases seemed to get better quite quickly after a few weeks and this might lead to mistaken ideas on the value of certain treatment.

Exclusion of organic disease such as true hypertrophic stenosis, preferably without operation, would seem of the first importance. As Davison (1951) has pointed out, experience is as necessary to the radiologist as to the clinician in these difficult cases.

Full calorie feeding, preferably at the breast, sedation, stomach wash-outs and perhaps the use of an antispasmodic, would seem the best means of tiding over the temporary upset. It is worth remembering that in earlier days many cases of true pyloric stenosis used to be kept alive by re-feeding after a vomit until this disease (also a self-limiting one) had burnt itself out.

\section{Conclusions}

Many explanations have been offered in the past for these obscure forms of vomiting in infants, such as hypertonia (Hess, 1914), autonomic imbalance, greed, over-activity and mucous gastritis. In this series, however, we have not been able to incriminate such factors, which are probably: symptoms of the underlying starvation due to the vomiting rather than a cause of it.

We feel that in most cases of vomiting without a demonstrable organic basis the most profitable line of management is to search for and correct feeding faults (often unsuspected underfeeding); then if this does not relieve the symptoms, one is usually left with a member of one of the two groups which we have described and for which we have suggested treatment. 


\section{Summary}

Vomiting of uncertain origin accounted for $18 \%$ of babies under 6 months of age admitted to hospital because of vomiting without diarrhoea. Forty-six such cases were studied.

When those cases found to be due to feeding difficulties (about half) were excluded, the remaining 22 fell into two well-defined groups termed persistent and non-persistent vomiting of uncertain origin respectively.

In persistent vomiting of uncertain origin the vomiting had an average duration of 29 weeks; normal expected weight was not regained until about the age of 1 year. Nursing in the vertical position and thickening of the feeds were effective therapeutic measures. Gastro-oesophageal incompetence is considered a possible causal factor.

In non-persistent vomiting of uncertain origin the average duration of vomiting was seven weeks; normal expected weight was regained by about 6 months of age. There were some clinical and radiological similarities to hypertrophic pyloric stenosis, but reasons are given for the belief that it is a different entity.

We are very grateful for help from Professor J. M. Smellie, Dr. C. G. Teall and the consultants of the Children's Hospital, Birmingham, and for permission to examine cases under their care. We are also indebted to Dr. Jean Mackintosh, of the Birmingham Maternity and Child Welfare Department, for help in tracing cases, and to the nursing staff of the Children's Hospital for their cooperation and constructive criticism.

\section{REFERENCES}

Armstrong, G. (1777). An Account of the Diseases most Incident to Children, p. 50. London.

Astley, R. (1952). Brit. J. Radiol., 25, 342.

Browne, D. (1931). Archives of Disease in Childhood, 6, 129.

Carré, I. J., Astley, R. and Smellie (1952). Lancet, 2,

Davison, G. (1951). Lancet, 2, 126.

Dewees, W. P. (1834). A Treatise on the Physical and Medical Treatment of Children, 5th ed., p. 369. Philadelphia.

Falle, E. de C. (1948). Lancet, 1, 794.

Field, C. E. (1941). Proc. roy. Soc. Med., 35, 59.

Finkelstein, H. (1919). Dtsch. med. Wschr., 45, 873.

Forssell, G. (1923). Amer. J. Roentgenol., 10, 87.

- (1939). Ibid., 41, 145.

Freudenberg, E. (1942). Schweiz. med. Wschr., 72, 405.

Henoch, E. (1889). Lectures on Children's Diseases, 4th ed., vol. 1 p. 126. Trans. by John Thomson. New Sydenham Soc., London.

Hess, A. F. (1914). Amer. J. Dis. Child., 7, 184.

Jacoby, N. M. (1946). Brit. med. J., 1, 721.

Kerley, C. G. (1920). N.Y. St. J. Med., 20, 345.

Koplik, H. (1913). N.Y. med. J., 97, 57.

Mann, N. M. and Anscombe, A. R. (1948). Lancet, 1, 966.

Mann, N. M. and Anscombe, A. R. (1948). Lancet, 1, 966. Ibid., 2, 556.

Meuwissen, T. and Slooff, J. P. (1934). Amer. J. Dis. Child., 48, 1304

Morse, J. L. (1911). Ibid., 1, 366.

Neuhauser, E. B. D. and Berenberg, W. (1947). Radiology, 48, 480.

Rocher, H. L. (1931). Bull. Soc. Pédiat. Paris, 29, 385.

Rotch, T. M. (1896). Pediatrics, vol. 2, p. 841. Edinburgh.

Sauer, L. W. (1924). Arch. Pediat., 41, 145.

Thompson, W. A. and Gaisford, W. F. (1935). Brit. med. J., 2, 1037

Uhr, E. (1932). Dtsch. Z. Chir., 235, 58.

Wood, B. S. B. (1951). Dissertation for the Degree of Doctor of Medicine, Oxford University. (1952). Lancet, 1, 28. 
Die Zerebrale Angiographie. By H. KRAYENBütH and H. R. Richter. (Pp. VIII + 213; 100 illustrations. D.M. 597.) Stuttgart: Georg Thieme. 1952.

One has no hesitation in commending this book to all interested in the central nervous system. It is fully illustrated with excellent reproductions of cerebral arteriograms, nearly all accompanied by line drawings with the principal vessels identified and the abnormalities clearly indicated.

A quick perusal of the illustrations would soon convince one of the value of cerebral angiography as a diagnostic procedure. In the years that have passed since Moniz performed the first carotid arteriogram (1927) many of the possibilities of the examination have been realized, as this volume shows. In particular much of the authors' recent work on the normal and pathological anatomy of the deep cerebral veins is included. It used to be believed that cerebral angiography was of no value in the localization of central tumours when pathological vessels were not demonstrable. However, now that the radiological anatomy of the deep veins has been described, it is possible to localize these tumours by the manner in which they dislocate veins even when the cerebral arteriogram is substantially normal. It is not reasonable, however, to expect more accuracy than is obtained by pneumography.
As a neuroradiologist I would like to have seen more of the lateral arteriograms accompanied by antero-posterior projections, but this could only have been done at the cost of reducing the number of cases reported.

The bibliography is comprehensive.

Residential Speech Therapy. Edited by C. WorsTerDroughr. (Pp. 150; illustrated. 15s.) London: Wm. Heinemann Medical Books Ltd. 1952.

Some children with defective speech, due to a variety of causes, need more observation and treatment than can be provided in one or two weekly attendances at an outpatient clinic. Moor House School was opened in 1947 for such patients, and this book is an account of its first two years' work and of the first 36 children who were accepted as residents. It is often difficult for outsiders to know what goes on in new and specialized institutions, hence the value of this account. It is truly original, for it describes what was observed without attempting any detailed survey of the work of others in the field of speech therapy, and those who have to deal with serious cases of this type will find the book interesting and useful. The literary style is clear, technical and unadorned: there are illustrations, tables, appendices and an index.

\section{Corrections}

The Editors regret that in the title of the paper by A. M. G. Campbell, Joan Guy and W. Grey Walter published in the December, 1952, issue of the Archives of Disease in Childhood $(27,507)$, the word "cytomegalic" was inserted. The correct title should be " Two Cases of Inclusion Encephalitis".

In the paper "Vomiting of Uncertain Origin in Young Infants," Archives of Disease in Childhood, 27,
562, the legend to Fig. 1 should read : "Comparison of average growth curves in persistent and non-persistent vomiting of uncertain origin."

The vertical lines (Max.) indicate the maximum deviation from the normal weight, which occurs at very different ages in the two groups.

The first four words of line 15 , column 2, page 563 should be deleted. 